\title{
AVALIAÇÃO ECONÔMICA PARA INSTALAÇÃO DE UM SISTEMA FOTOVOLTAICO NA UNIVERSIDADE DO OESTE PAULISTA - UNOESTE, EM PRESIDENTE PRUDENTE - SP.
}

\author{
Jonathan William Neves Costa, Naama Cristina dos Santos
}

Universidade do Oeste Paulista, Curso de Administração, Presidente Prudente, SP. E-mail: jonathanwncosta@outlook.com

\begin{abstract}
RESUMO
A utilização de recursos minerais e combustíveis fosseis como, carvão mineral e petróleo para geração de energia ainda é elevada, ocasionando danos permanentes ao ecossistema. Com o intuito de reverter à situação o uso fontes de energia renovável vem se intensificando em nível global. O ensaio elaborado analisou o custo para implantação de painéis fotovoltaicos na geração de energia em uma instituição privada. Os objetivos trabalhados no projeto estavam voltados em analisar, por meio do uso das técnicas do período para retorno do investimento (payback), a Taxa Interna de Retorno (TIR) e o Valor Presente Líquido (VLP) aspectos financeiros e analisar os potenciais benefícios provenientes do uso de painéis. $A$ metodologia trabalhada foi à abordagem qualiquantitativa com caráter exploratório, tendo como apoio a pesquisa bibliográfica, aplicando-se o contexto em um estudo de caso na Universidade do Oeste Paulista (Unoeste) na cidade de Presidente Prudente, estado de São Paulo. Os resultados asseveram uma produção de energia limpa, sem agressão ao meio ambiente e com redução da emissão de gases poluidores, fortalecendo as práticas voltada a gestão sustentável e, promovendo o uso de políticas ligadas à responsabilidade socioambiental. Devido ao longo período de vida útil dos equipamentos, as placas se mostram viáveis visto que a amortização do valor inicial investido ocorre em poucos anos. Conclui-se a existência de viabilidade econômica, com a adoção de um sistema solar para geração de energia, propiciando impactos benéficos para a própria instituição, seus colaboradores, alunos e a comunidade a qual está inserida.
\end{abstract}

Palavras-chave: Sustentabilidade. Energia Renovável. Sistemas Fotovoltaicos.

\section{ECONOMIC EVALUATION FOR INSTALLATION OF A PHOTOVOLTAIC SYSTEM IN THE UNIVERSITY OF OESTE PAULISTA - UNOESTE, IN PRESIDENTE PRUDENTE - SP.}

\begin{abstract}
The use of mineral resources and fossil fuels such as mineral coal and oil for power generation is still high, causing permanent damage to the ecosystem. In order to reverse this situation the use of renewable energy sources has been intensified globally. This paper has analysed the cost for implementing photovoltaic panels to generate energy in a private institution. The objectives used on the project were focused on analyse the financial aspects by using techniques of the period for investment return (payback), Internal Rate of Return (IRR) and Net Present Value (NPV) and analyse the potential benefits from the use of panels. The methodology was a quali-quantitative approach of exploratory nature, having as support the bibliographic research, in the context of a case studied at the University of Oeste Paulista (Unoeste) in the city of Presidente Prudente, São Paulo. The results assure a clean energy production without aggression against the environment and reduction of the polluting gases emission, strengthening the practices aimed at sustainable management and, promoting the use of policies related to social and environmental responsibility. Due to the long life of equipment, the solar panels are proven to be viable since the amortization of the initial value invested occurs in few years. The conclusion is the existence of economic viability with the adoption of a solar system for power generation, providing beneficial impact for the institution itself, its employees, students and the community in which it is inserted.
\end{abstract}

Key words: Sustainability. Renewable energy. Photovoltaic Systems. 


\section{CENÁRIO ENERGÉTICO RENOVÁVEL}

O conceito de Planeta verde é um dos temas discutidos nas organizações e sociedade pelo fato de que hoje se tem o alto índice de consumo de recursos provenientes dos ecossistemas, o que acaba gerando a degradação do meio ambiente e a escassez de matéria. A demanda demasiada no consumo dos recursos naturais utilizados pelo homem tem se intensificado nas últimas décadas e as práticas que visam reverter os impactos gerados estão ausentes no cotidiano da sociedade. Nesse sentido, Bottini (2005, p. 62), considera que:

\section{0 bem-estar humano rumo ao desenvolvimento sustentável dependem essencialmente dos ecossistemas da Terra. 0 modo como estes são afetados pelas atividades humanas tem consequências sobre o fornecimento de seus serviços - incluindo alimento, água potável, combustível e fibras -, sobre a prevalência de enfermidades, a e a magnitude de inundações e de secas, e sobre o clima, tanto local como global.}

A fome de consumo e o desenvolvimento exacerbado são alguns dos causadores da escassez dos recursos naturais. Tendo-se a necessidade de se buscar fontes renováveis e aplica-las em cadeia global a fim de minimizar os impactos gerados há décadas para a perenidade dos recursos e em prol a sobrevivência humana. Um dos campos trabalhados para alcance do desenvolvimento sustentável e que está cada vez mais perceptível é o uso de recursos renováveis na geração de energia, visto que ao optar por tais recursos temos a diminuição do uso de combustíveis fosseis, dos quais detém um alto percentual na poluição do Planeta.

O Programa das Nações Unidas para o Desenvolvimento no Brasil propõe os Objetivos de Desenvolvimento Sustentável (ODS), onde o sétimo objetivo trata-se exatamente da promoção de energia, ou seja, "garantir acesso à energia barata, confiável, sustentável e renovável para todos" (PNUD, 2015). Com isso espera-se, portanto investimentos para a produção de energia limpa, confiável e trabalhando em estudos para produção de equipamentos em âmbito nacional visando o uso de recursos naturais renováveis.

"As fontes renováveis de energia são aquelas consideradas inesgotáveis para os padrões humanos de utilização. Podemos utilizalas continuamente e nunca se acabam, pois sempre se renovam."(VILLALVA; GAZOLI, 2012, p. 16). As fontes renováveis já estão presentes no Brasil, as mais utilizadas são a luz solar para a produção de energia ou apenas como sistema de aquecimento de água, a hidrelétrica, eólica e a biomassa, com o intuito de ter em âmbito nacional uma produção de energia limpa, com redução quanto à emissão de dióxido de carbono na atmosfera e outros causadores do efeito estufa e degradação do meio ambiente.

No Brasil desde abril de 2012 o consumidor pode gerar em suas residências sua própria energia por meio de fontes renováveis como a solar e eólica isto de acordo com a Resolução Normativa ANEEL no 482/2012, considerada como Micro e Mini geração de energia, tendo-se assim a união entre economia financeira e consciência quanto ao consumo socioambiental. Desta forma Bertoncello, Souza e Silva (2015) afirmam que:

(...) a microgeração
distribuída por ser
compreendida como uma
central geradora, com
potência menor ou igual a
$100 \mathrm{~kW}$, que utilize fontes
renováveis de energia
elétrica, como a solar e
que estejam conectadas à
rede de distribuição da
concessionária, por meio
das instalações da unidade
consumidora, diferindo a
minigeração, por esta ter
potência maior que 100
kW, mas menor ou igual a
$1 \mathrm{MW}$.

De acordo com Aldabó (2012, p. 9) a luz solar está "disponível para a humanidade desde o surgimento da vida na Terra, a energia solar nunca foi aproveitada de forma tão eficiente (...)." A luz solar está sendo utilizadas na geração de energia de forma que: 


\begin{abstract}
(...) os sistemas fotovoltaicos têm a capacidade de captar diretamente a luz solar e produzir corrente elétrica. Essa corrente é coletada e processada por dispositivos controladores e conversores, podendo ser armazenada em baterias ou utilizada diretamente em sistemas conectados à rede elétrica (...). (VILLALVA; GAZOLI, 2012, p. 21).
\end{abstract}

As placas fotovoltaicas podem ser implantadas nos telhados, fachadas das organizações, residências, edifícios para captação e geração de energia, e a grande importância dada à adoção de sistemas de geração de energia com uso de placas solares vem exatamente da localização do País em possuir um clima tropical com vasta incidência natural de luz solar, o que intensifica o potencial de projetos como este.

A energia eólica, "a energia do vento (...), foi uma das primeiras formas de aproveitamento tecnológico de uma fonte primária de energia de que o ser humano fez uso." sendo está mais uma fonte de energia com grande potencial no Brasil.

Além de ser uma fonte naturalmente renovável e de baixos impactos ambientais, a energia eólica pode ser utilizada para a geração de eletricidade tanto em sistemas isolados da rede elétrica, quanto em sistemas a ela conectados, em centrais dos mais variados portes. Assim, pode-se ter um sistema isolado para atender um único consumidor residencial ou uma vila com algumas dezenas ou centenas de consumidores (...). (GOLDEMBERG et. al., 2012, p. 73)

A produção é realizada por meio de aerogeradores e em locais com grande abundância de ventos a utilização deste recurso é uma forma sustentável de se trabalhar com prejuízos mínimos ao meio ambiente.
A biomassa é outro recurso renovável utilizado pela sociedade e de acordo com Souza, Pereira e Pavan (2004) “(...) é definida como toda matéria orgânica de origem animal e vegetal, formada pelo processo de fotossíntese, o qual ocorre na presença da luz solar." A matéria orgânica que antes era problema por conta do descarte, hoje se tem como aliado do meio ambiente visto que este recurso é utilizado na geração de energia. Um exemplo de matéria utilizada neste processo o bagaço de cana. Produtores de açúcar e álcool reaproveitam o bagaço da cana para gerar energia para movimentar suas máquinas durante a produção, sendo este um processo limpo, renovável e com grande potencial em território nacional.

A Matriz energética do Brasil é renovável visto que sua geração de energia é basicamente baseada na utilização de recursos hídricos, com inúmeras usinas e reservatórios. Uma usina hidrelétrica é "uma obra de construção civil e de montagem de equipamentos eletromecânicos, cujo objetivo é a geração de energia elétrica por meio de aproveitamento da energia potencial hidráulica." (SANTOS, 2013, p. 182) uma produção com poucos impactos ao meio ambiente, tendo como matéria prima a água represada que no decorrer do processo transforma a energia mecânica em elétrica.

Mundialmente temos inúmeros meios e recursos renováveis à disposição para geração de energia que causem mínimos ou nenhum impacto ambiental dos quais geram a degradação do Planeta e a escassez de recursos para satisfazer as necessidades para 0 bem-estar presente e futuro.

A problemática do projeto está em apresentar qual a viabilidade econômica dos sistemas fotovoltaicos instalados em uma unidade piloto na Universidade do Oeste Paulista - UNOESTE? Onde acredita-se que o aproveitamento a luz solar para geração de energia solar é uma forma de gerar economias monetárias para a organização e benefícios para o ecossistema, visto que a luz solar é um recurso inesgotável e as placas possuem uma vida útil que gira em torno de 25 anos, tempo para quitar os equipamentos e obter economias com a produção e reduz as emissões de gases poluidores que danificam o Planeta.

O ensaio elaborado visa analisar a viabilidade econômica para implantação de painéis fotovoltaicos na geração de energia em uma instituição privada onde a base de estudo foi 
em aprofundar a compreensão do tema energia renovável; analisar os potenciais benefícios provenientes do uso de painéis fotovoltaicos e com as técnicas do período para retorno do investimento (payback), a Taxa Interna de Retorno (TIR) e o Valor Presente Líquido (VLP) demonstrar os aspectos financeiros da implantação

\section{MÉTODOS E PROCESSOS}

A metodologia neste ensaio com o intuito de se alcançar o objetivo pretendido será com uma abordagem qualiquantitativa, uma descrição mais profunda do estudo para melhor compreensão e também terá em sua base a coleta de dados para análise e interpretação posterior (MASCARENHAS, 2012).

Com caráter exploratório a pesquisa visa à familiarização com tema abordado, aprofundando os conhecimentos. A fim de se obter respostas aos problemas propostos recorremos à pesquisa bibliográfica com consulta em livros, artigos científicos, sites especializados no assunto, identificando referências que assegurem nossas ideias sobre a utilização de fontes de energia renovável, mais especificamente a energia solar. (CERVO; BERVIAN; DA SILVA, 2007).

O ensaio se dará por um estudo de caso na Unoeste (Universidade do Oeste Paulista) é uma Instituição de Ensino Superior exercendo atividades de ensino, pesquisa e extensão atuando desde 1972 na cidade de Presidente Prudente. Conta com aproximadamente $19 \mathrm{mil}$ alunos e 2 mil funcionários em dois Campus e uma ampla infraestrutura, sendo o Campus I funcionando com os cursos das áreas da Saúde, Exatas e da Terra, Humanas, Biológicas, Ciências, Letras, Artes e Educação e o Campus II os cursos de Ciências Agrárias, da Saúde, Exatas e da Terra, Humanas, Sociais e Aplicadas, Engenharias, e Linguística, Letras e Artes desses 57 cursos presenciais e 10 na modalidade à distância (EAD).

Hoje a Unoeste além de cursos de Graduação, conta também com cursos de PósGraduação, Mestrado, Doutorado, Especializações e o Núcleo de Educação a Distância (Nead). Com sua ampla estrutura física criada justamente para manter o contato entre estudantes, funcionários e comunidade ao meio ambiente natural, composto por uma ampla cadeia de fauna e flora e promovendo tal interação a Unoeste demonstra sua conscientização em prol ao desenvolvimento sustentável, conservação e respeito ao meio ambiente.

O estudo econômico utilizou de algumas técnicas orçamentárias para analise da viabilidade do projeto. O payback que segundo Gitman (2010 p. 366) “(...) é o tempo necessário para que a empresa recupere o investimento inicial em um projeto, calculado a partir das entradas de caixa", ou seja, qual o período de tempo (anos, meses e dias) necessário para que as entradas de caixa se igualem ao valor inicial investido. Já a técnica do VPL “(...) é a diferença entre o valor descontado do fluxo de caixa para a data do investimento inicial e o valor do investimento inicial de um projeto" (MEGLIORINI; VALLIM, 2009, p. 129).

Após os cálculos alguns critérios são utilizados para determinar a viabilidade do projeto. Um dos parâmetros usados é o de que se o VPL for $\geq 0$ pode ser considerado aceito, onde quanto maior o valor resultante do VPL mais vantajoso é o projeto. De acordo com Gitman (2010, p. 370) "Se o VPL for maior que $\$ 0$, a empresa obterá um retorno maior do que o custo de seu capital". Proporcionando benefícios financeiros à empresa, aumentando seu valor de mercado e recursos monetários inclusive para os investidores.

A TIR de acordo com Megliorini e Vallim (2009, p. 131), "é uma taxa de desconto que iguala o valor presente do fluxo de caixa ao valor do investimento inicial de um projeto". Em outras palavras seria qual a taxa de retorno do projeto pretendido e ainda para cálculo da TIR não se faz necessário uma taxa mínima, pois a resolução matemática propicia uma taxa e o que pode ser feito é uma comparação com a taxa já existente.

\section{ENERGIA FOTOVOLTAICA}

A Energia Solar vem ganhando um espaço significativo nos últimos anos, sendo está captada e transmitida por meio dos painéis fotovoltaicos e "o efeito fotovoltaico, característico de alguns materiais semicondutores, pode ser convenientemente aproveitado na produção das chamadas células fotovoltaicas, que em conjunto comporão os respectivos painéis" (FERREIRA, 2014, p.46), que tendem a serem baixos os volumes de emissão nas etapas industriais desse setor, inclusive no final do seu ciclo de vida, podem ser reaproveitados ou reciclados mais de $85 \%$ dos seus componentes, contribuindo assim ainda mais com a redução dos impactos ambientais ao longo do tempo. 
(...) a geração solar fotovoltaica, mesmo que de menor porte, tem tido muito mais aplicação não só em países desenvolvidos, como Estados Unidos, Japão e Alemanha, mas também em países em desenvolvimento, principalmente para alimentação de pequenos sistemas isolados, em projetos-piloto (...) (REIS; FADIGAS; CARVALHO, 2011, p.21).

A busca por esse tipo de equipamento vem crescendo constantemente, propiciando a queda nos custos, sendo possível atingir uma escala ainda maior quanto ao uso. Os custos com operação e manutenção são muito pequenos, pois o sistema é autônomo, o controle é feito, pelo próprio inversor de frequência e a manutenção é basicamente a remoção da poeira da superfície dos painéis. Benefícios ambientais que são evidentes ao se comparar a energia solar com as fontes não renováveis dentre eles o custos de extração, geração transmissão, distribuição e uso final. Leva-se em consideração que não emitem gases poluentes, líquidos ou sólidos.

Baraniuk (2016) afirma que "conforme o custo de construção de usinas solares cai, o mundo vem assistindo a uma multiplicação de megainstalações". Pelo fato das grandes organizações desembolsarem um alto custo com energia, à busca por reduzir e manter esses gastos a um custo menor é um fator de grande relevância para adoção de sistemas solares.

\section{ASPECTOS ECONÔMICO, SOCIAL E AMBIENTAL}

Quando se fala em sustentabilidade, surge a preocupação das empresas em como colaborar de alguma forma. Esse tema de grande relevância tem sido discutido atualmente. As empresas agem transformando e exercendo influência sobre os recursos humanos, a sociedade e o meio ambiente, além de possuírem recursos financeiros, tecnológicos. Desta forma, uma postura é necessária para se atuar e colaborar com essas áreas seja nas esferas éticas, transparência e justiça social.

Segundo Mendes (2009), aspecto econômico refere-se à eficácia econômica avaliada em termos macrossociais, visando não somente a lucratividade empresarial, mas também o desenvolvimento econômico equilibrado, ou seja, é a busca pelo equilíbrio entre o uso de recursos naturais e a produção de riqueza. Há uma interligação entre os aspectos econômicos e ambientais que geram a ecoeficiência na qual representa à forma correta de utilização dos equipamentos de produção que são aplicados a tecnologia, gerando assim a redução dos impactos ambientais.

De acordo com Siqueira (2013), o aspecto ambiental é mais do que um mero equilíbrio ecológico, do uso correto dos recursos naturais pelo homem ou através da diminuição dos impactos causados pelos empreendimentos ao meio ambiente, levando em consideração as inovações tecnológicas e os benefícios proporcionados desde que não provoquem desequilíbrio para os sistemas naturais comprometendo as gerações futuras. Entende-se que a organização ou a sociedade deva buscar caminhos, opções corretas de planejamento para uso de novas tecnologias que minimizem tais impactos e o uso correto dos recursos sejam eles renováveis ou não.

Mendes (2009) relata que um aspecto social, trata-se da abrangência das necessidades de recursos materiais e não materiais, na qual o objetivo maior é a igualdade na distribuição de renda, procurando melhorar de certa forma os direitos e as condições da sociedade, ampliando a homogeneidade social, possibilitando qualidade de vida e igualdade no acesso aos recursos e serviços sociais. Referencia-se ao capital humano seja de um empreendimento, comunidade, enfim da sociedade como um todo, não implicando na eliminação da livre iniciativa, mas permitindo que diversas camadas sociais dentro de uma mesma sociedade usufruam de condições para o pleno desenvolvimento pessoal.

Nesse sentido, de forma direta ou indiretamente as empresas utilizam recursos naturais, mas ao adotar uma postura sustentável, ela passa a utilizar esses recursos de forma consciente, exercendo influência social com atitudes diferenciadas, promovendo benefícios para as partes interessadas, além de contribuir para o meio ambiente.

\section{DISCUSSÃO ECONÔMICA}

Este estudo demonstra a viabilidade de investimentos no setor energético, mas especificamente na geração de energia por meio 
de recursos renováveis. Em meio a tantas prospecções negativas quanto à degradação do meio ambiente, o uso de recursos renováveis se faz necessário. Os sistemas fotovoltaicos reagem à luz solar (recurso renovável ilimitado) que no Brasil possui um grande nível de irradiação, sem impactos visto que sua geração é limpa, sem emissão de gases poluidores, e toda a cadeia do sistema fotovoltaico pode ser conectada a rede elétrica de distribuição conforme a resolução 482/2012 da ANEEL.

Analisar a viabilidade de um projeto se faz "(...) considerando todos os aspectos econômicos e financeiros relacionados à sua performance, bem como a sustentabilidade". (MACEDO, 2014, p. 8). Para analise do projeto, serviram de apoio os critérios apresentados na Tabela 1.
Tabela 1 - Resumo dos dados financeiros

CRITÉRIOS VALORES

\begin{tabular}{ll}
\hline $\begin{array}{l}\text { Valor do investimento } \\
\text { (R\$) }\end{array}$ & $\mathrm{R} \$ 174.440,45$ \\
Geração anual (kWh) & 42.000 \\
Valor do kWh & 0,77 \\
Benefício anual (R\$) (1) & $\mathrm{R} \$ 32.340,00$ \\
TJLP Selic (\%) & $14,00 \%$ \\
\hline Período de tempo & 5 anos \\
\hline Fonte: elaborado pelos autores. (1) O benefício anual \\
é obtido através da seguinte equação: [benefício anual \\
= geração anual $x$ valor do kWh].
\end{tabular}

A Tabela 1 está composta pelo valor total do investimento de $\mathrm{R} \$ \mathbf{1 7 4 . 4 4 0 , 4 5}$, sendo este composto por um kit energia solar de $10,6 \mathrm{kWp}$ no valor de $\mathrm{R} \$ 64.706,87$, um kit de energia solar de $15,9 \mathrm{kWp}$ no valor de $94.733,58$ e $\mathrm{R} \$$ $15.000,00$ de mão de obra para instalação do sistema. O orçamento foi obtido na Empresa Matsuda Equipamentos Ltda. na cidade de Presidente Prudente. Os equipamentos possuem a capacidade de geração média de energia por mês de 3.500 kWh, ou seja, uma produção anual de $42.000 \mathrm{kWh}$ para uma área de ocupação de $154 \mathrm{~m}^{2}$. O valor em $\mathrm{kWh}$ é de $\mathrm{R} \$ 0,77$ de energia. O valor do benefício anual (R\$32.340,00), foi obtido pela multiplicação entre o valor do kWh e o valor de geração anual. A taxa de desconto utilizada foi a do Sistema Especial de Liquidação e de Custódia (Selic), que na data do presente artigo está em $14,00 \%$.

Tabela 2 - Payback, Valor Presente Líquido e Taxa Interna de Retorno.

\section{TÉCNICAS \\ DADOS}

\begin{tabular}{ll}
\hline Payback simples & 4 anos 2 meses e 5 dias \\
VPL - Valor Presente Líquido & (R\$ 28.985,86) \\
TIR - Taxa Interna de Retorno & $7,28 \%$ ao ano \\
\hline
\end{tabular}

Fonte: elaborado pelos autores

Na Tabela 2 temos os resultados obtidos a partir da aplicação das técnicas financeiras. 0 primeiro item observado é o payback, que segundo Gitman (2010, p. 366) “(...) é o tempo necessário para que a empresa recupere $o$ investimento inicial em um projeto, calculado a partir das entradas de caixa", ou seja, qual o período de tempo (anos, meses e dias) necessário para que as entradas de caixa se igualem ao valor inicial investido.

Está técnica é muito utilizada em finanças, pois além de fornecer os prazos de recuperação do capital aplicado, também é uma tem uma forma simples de aplicação e compreensão. Para o esboço aqui apresentado o tempo de retorno é do capital é de 4 anos e 2 
meses e 5 dias, período aceitável para a proposta visto que a vida útil das placas é de aproximadamente 25 anos, neste caso a Unoeste após o tempo de recuperação do investimento ainda restariam cerca de 20 anos para usufruir dos equipamentos.

O segundo item observado é o VPL “(...) é a diferença entre o valor descontado do fluxo de caixa para a data do investimento inicial e o valor do investimento inicial de um projeto" (MEGLIORINI; VALLIM, 2009, p. 129). Após os cálculos alguns critérios são utilizados para determinar a viabilidade do projeto.

De acordo com Gitman (2010, p. 370) "Se o VPL for maior que $\$ 0$, a empresa obterá um retorno maior do que o custo de seu capital". Proporcionando benefícios financeiros à empresa, aumentando seu valor de mercado e recursos monetários inclusive para os investidores.

Na resolução dos cálculos temos um fator negativo, visto que o Valor Presente Líquido encontrado é de ( $R \$ 28.985,86)$, deixando de ser vantajoso do ponto de vista orçamentário. Vários aspectos podem ser levados em consideração em especial as condições econômicas vivenciadas no país atualmente e claro o alto valor das placas, visto que tais equipamentos são produzidos fora do País o que encarece seu custo para importação.

O terceiro e último item calculado é a Taxa Interna de Retorno (TIR), considerada umas das técnicas mais sofisticadas no âmbito financeiro. A TIR de acordo com Megliorini e Vallim (2009, p. 131), "é uma taxa de desconto que iguala o valor presente do fluxo de caixa ao valor do investimento inicial de um projeto". Em outras palavras seria qual a taxa de retorno do projeto pretendido.

O percentual obtido para a proposta das placas fotovoltaicas é de $7,28 \%$ ao ano, taxa relativamente inferior à trabalhada (SELIC) no valor de $14,00 \%$ ao ano. Gitman (2010) afirma que "Se a TIR for maior que o custo de capital, deve-se aceitar o projeto, agora caso o ocorra o contrario, ou seja, a TIR for menor que o custo de capital o projeto deve-se ser recusado". Analisando os critérios sugeridos temos o não aceite do projeto devido ao seu Valor Presente Líquido e sua Taxa Interna de Retorno.

\section{CONCLUSÃO}

Em suma, o presente esboço apresentou o cenário energético renovável que está ganhando força e conquistando o mundo, onde a luz solar propicia a geração de energia elétrica de tal maneira que promove uma redução em grande escala de gases responsáveis pelo efeito estufa, produz energia limpa e renovável, com baixa manutenção e benefícios monetários a quem adere ao s sistemas.

Os painéis fotovoltaicos são de fácil instalação e manutenção, sua vida útil gira em cerca de 25 anos, dando ao investidor um tempo considerável para uso e sem agressões ao meio ambiente, fornecem uma energia não contaminante além de sua instalação ser adaptável se adequando de acordo com a necessidade do investidor.

$\mathrm{Na}$ avaliação financeira chegou-se a um payback de 4 anos 2 meses e 5 dias, proporcionado ainda aproximados 20 anos de uso dos equipamentos. O projeto tem seu lado negativo no momento, devido aos altos valores dos equipamentos e a situação econômica vivida pelo país atualmente o que acaba por deixar de promover vantagens econômicas, todavia a sociedade está presenciando o fortalecimento quanto ao uso dessa fonte para geração de energia o que em decorrência a tendência é a queda no custo dos equipamentos estimulando sua adoção.

\section{REFERÊNCIAS}

AGÊNCIA NACIONAL DE ENERGIA ELÉTRICA. Geração Distribuída. Disponível em: $<$ http://www.aneel.gov.br/destaquesdistribuicao/-

/asset_publisher/zRFisxBAsbz9/content/geracaodistribuida-introduc-

1/656827?inheritRedirect=false\&redirect=http\%3 A\%2F\%2Fwww.aneel.gov.br\%2Fdestaques-

distribuicao\%3Fp_p_id\%3D101_INSTANCE_zRFisx BAsbz9\%26p_p_lifecycle\%3D0\%26p_p_state\%3D normal\%26p_p_mode\%3Dview\%26p_p_col_id\%3 Dcolumn-

2\%26p_p_col_pos\%3D2\%26p_p_col_count\%3D6 >. Acesso em: 12 out. 2016.

ALDABÓ, R. Energia solar. São Paulo: Artliber, 2012.

BAPTISTA, V. F. A relação entre o consumo e a escassez dos recursos naturais: uma abordagem histórica. Revista Saúde \& Ambiente, Duque de Caxias, v.5, n. 1, p.08-14, jan./jun. 2010.

BERTONCELLO, A. G.; SOUZA, M. M.; SILVA, N. S. Necessidade do fortalecimento de políticas públicas para implantação de energia renovável: estudo de caso FATEC Presidente Prudente. 
Revista Nacional de Gerenciamento de Cidades, v. $03, \quad$ n. $16, \quad$ p. 138-156. 2015. https://doi.org/10.17271/2318847231620151015 BOTTINI, R. L. (trad.) Ecossistemas e bem estar humano: relatório do grupo de trabalho da estrutura conceitual da avaliação ecossistêmica do milênio. São Paulo: SENAC São Paulo, 2005.

BARANIUK, C. Por que as gigantes da tecnologia estão investindo em energia solar e eólica? Disponível em: <http://www.bbc.com/portuguese/vert-fut37655484> Acesso em: 26 out. 2016.

CARVALHO, A. A. Uma solução envolvendo painéis fotovoltaicos para o suprimento de energia ao LAFAE conforme um sistema de gestão ambiental, Rio de Janeiro, 2007. Disponível em: < http: // monografias.poli.ufrj.br/monografias/monopoli 1000424.pdf >. Acesso em: 27 jul. 2016. CERVO, A. L.; BERVIAN, P. A.; DA SILVA, R. Metodologia científica. 6.ed. São Paulo: Pearson Prentice Hall, 2007.

CHIAVENATO, I. Gestão financeira: uma abordagem introdutória. 3.ed. Barueri, SP: Manole, 2014.

Energia limpa e acessível. Programa das Nações Unidas para o Desenvolvimento. Disponível em: < http://www.br.undp.org/content/brazil/pt/home /post-2015/sdg-overview/goal-7.html>. Acesso em: 20 set. 2017.

FERREIRA, A. D. D. Habitação autossuficiente: interligação e integração dos sistemas alternativos. Rio de Janeiro: Interciência, 2014.

FONSECA ,L. F. O. D.Viabilidade econômica da implantação de painéis fotovoltaicos para redução do consumo de energia elétrica no Campus Central da Universidade Federal do Rio Grande do Norte, junho de 2016. Disponível em:<http://monografias.ufrn.br/jspui/bitstream/ 123456789/2583/1/Energia\%20FotovoltaicaArtig o.pdf>. Acesso em: 14 out. 2016.

GITMAN, L. J. Princípios de administração financeira. São Paulo: Pearson Prentice Hall, 2010.

GOLDEMBERG, J. et. al. Energias Renováveis. São Paulo: Blucher, 2012.

GUERRA, A. J. T.; CUNHA, S.B. da. (orgs.). Impactos ambientais urbanos no Brasil. 6. ed. Rio de Janeiro: Bertrand Brasil, 2010.

LOURENÇO, M. L.; ,D. Sustentabilidade social e desenvolvimento sustentável, 2013. Disponível em:<http://editora.unoesc.edu.br/index.php/rac e/article/viewFile/2346/pdf>. Acesso em: 13 out. 2016.
MACEDO, J. de. J. Analise de projetos e orçamento empresarial. Curitiba: InterSaberes, 2014.

MAY, P. H.; LUSTOSA, M. C.; VINHA, V. da. (orgs.). Economia do meio ambiente: teoria e prática. Rio de Janeiro: Elsevier, 2003.

MASCARENHAS, S. A. Metodologia científica. São Paulo: Pearson Education do Brasil, 2012.

MEGLIORINI, E; VALLIM, M. A. Administração

financeira: uma abordagem brasileira. São Paulo: Pearson Prentice Hall, 2009.

MENDES, J. M. G. Dimensões da Sustentabilidade, $2009 . \quad$ Disponível em:<http:www.santacruz.br/v4/download/revist a-acadêmica/13/cap5.pdf>. Acesso em: 13 out. 2016.

POTIGUAR, F. Sustentabilidade empresarial, econômico-social-ambiental, 2011. Disponível em:

<http://responsabilidadesocial.com/artigo/suste ntabilidade-empresarial-economica-social-

ambiental/>. Acesso em: 04 ago. 2016.

RATTNER, H. O esgotamento dos recursos naturais: catástrofe ou interdependência? Revista Administração de Empresas, São Paulo, v. 17, n. 2, p.15-21, mar./abr., 1977. https://doi.org/10.1590/s0034-

75901977000200002

REIS, L. B. dos.; FADIGAS, E. A. A.; CARVALHO, C. $E$. Energia, recursos naturais e a prática do desenvolvimento sustentável. Barueri,SP: Manole, 2005.

SANTOS, M. A. dos. (org.). Fontes de energia nova e renovável. Rio de Janeiro: LTC, 2013.

SIQUEIRA, P. O Princípio da Sustentabilidade e o Terceiro Setor: Uma relação necessária para construção de uma sociedade livre, justa e solidária, 2013.2 Disponível em:<http:www.publicadireito.com.br/artigos/?co $d=348 a 38 c d 25 a b e a b 0>$. Acesso em: 12 out. 2016.

SOUZA, S. N. M. de.; PEREIRA, W. C.; PAVAN, A. A. Custo da eletricidade gerada em conjunto motor gerador utilizando biogás da suinocultura. In: ENCONTRO DE ENERGIA NO MEIO RURAL, 5., 2004, Campinas. Disponível em: $<$ http://www.proceedings.scielo.br/scielo.php?sc ript=sci_arttext\&pid=MSC0000000022004000100 $042 \&$ Ing $=e n \& n r m=a b n>$. Acesso em: 05 jun. 2016.

SACHS, W. Environment and Human Rights Society for International Development 47-1(p. 4249), 2004. 
VASCONCELOS, J. Responsabilidade social: o papel das empresas, Campina Grande, 2009. Disponível em: <http

//www.fiepd.com.br/artigos/2009/09/03/respon sabilidade_social_o_papel_das_empresas $>$.

Acesso em: 03 ago. 2016.

VILLALVA M. G.; GAZOLI, J. R. Energia solar fotovoltaica: conceitos e aplicações. São Paulo: Érica, 2012.

UNIVERSIDADE DO OESTE PAULISTA. A Unoeste. Disponível em: <http://www.unoeste.br/>. Acesso em: 03 abr. 2016.

XAVIER, G. A. Análise das externalidades da geração fotovoltaica distribuída no Brasil. Viçosa, 2015. Disponível em: <http: //www.locus.ufv.br/handle/123456789/7331>. Acesso em: 12 jul. 2016.

Recebido para publicação em 09/07/2017

Revisado em 15/07/2017

Aceito em 02/08/2017 